\title{
LA PERÍFRASIS IR A + INFINITIVO Y LA EXPRESIÓN DE LA POSTERIORIDAD EN EL HABLA CULTA DE COSTA RICA
}

Petr Pitloun

\begin{abstract}
RESUMEN
En esta investigación se describen los usos de la perífrasis verbal ir a + infinitivo en el habla culta de Costa Rica. Además, se averigua qué posición ocupa esta construcción entre las formas que se usan para denotar acciones posteriores tanto al momento del habla como a un punto de referencia anterior al momento en que se habla.

Se trata de un estudio descriptivo que se realiza sobre la base del material recogido según las pautas establecidas para el Proyecto de estudio coordinado de la norma lingüística culta de las principales ciudades de Iberoamérica y de la Península Ibérica.

Se llega a la conclusión de que la perífrasis ir a + infinitivo se emplea principalmente (el 64,7\% del total de todos los casos registrados) con el auxiliar en presente de indicativo para expresar acciones posteriores al momento en que se habla. En general, sus valores temporales predominan significativamente sobre los no temporales. Al mismo tiempo se concluye que esta construcción es la forma más usada para expresar acciones futuras vistas tanto desde el momento del habla como desde un punto pasado.

Palabras clave: español de Costa Rica, perífrasis verbales, perífrasis ir a + infinitivo, expresión del futuro, futuro de indicativo.
\end{abstract}

\begin{abstract}
The purpose of this investigation is to describe the use of the periphrastic construction ir a + infinitive in cultivated Spanish of Costa Rica. Furthermore, the study aims to find out the position this construction occupies among the forms that are used to indicate future events with reference both to the speech point and to a time point anterior to the act of speech.

It is a descriptive study based on the material collected within the framework of the Project of Coordinated Study of the Standard Linguistic Norm of the Principal Cities of Latin America and Spain.

Findings are that the periphrastic construction ir a + infinitive is used mostly (in $64,7 \%$ of all documented cases) with the auxiliary verb in present indicative to express future events with reference to the speech point. In general, the temporal use of this construction prevails significantly over its non-temporal use. Results also indicate that it is the most frequent form among the forms used to indicate future events referred both to the speech moment and to some past time point.

Key words: Spanish of Costa Rica, periphrastic constructions, periphrastic construction ir $a+$ infinitive, expression of the future, future indicative.
\end{abstract}

Dr. Art. Petr Pitloun. Profesor del Departamento de Lenguas Románicas de la Universidad de Bergen, Noruega. Correo electrónico: petrpitloun@yahoo.com

Recepción: 25-10-2004

Aceptación: 10-5-2005 


\section{Introducción}

En este trabajo se busca describir los usos de la perífrasis verbal ir a infinitivo en el habla culta de Costa Rica. Además, se propone averiguar qué posición ocupa en esta variante del español actual entre las formas que se usan para expresar acciones posteriores tanto al momento del habla como a un punto de referencia anterior al momento en que se habla.

La investigación se realiza sobre la base del material recogido por Yamileth Solano, según las pautas establecidas para el Proyecto de estudio coordinado de la norma lingüística culta de las principales ciudades de Iberoamérica y de la Península Ibérica, cuyo iniciador fue, en 1964, Juan Manuel Lope Blanch. El propósito de este proyecto ha sido

\footnotetext{
el análisis y descripción de las realidades idiomáticas específicas que caracterizan a cada uno de los países que tienen el español como lengua oficial: se podría llegar así al conocimiento de la norma hispánica común, es decir al conocimiento de la 'unidad dentro de la diversidad', de la 'unidad variada' o ,'variedad uniforme' (...) (R. Iuliano 1975: 59).
}

El material de Solano está constituido por 34 entrevistas, que corresponden a casi 18 horas de grabación. Los informantes fueron seleccionados atendiendo a varios factores socioculturales: a) todos son del área metropolitana de San José o son residentes en esta zona desde los cinco años de edad; b) todos tienen educación superior; c) todos hicieron su enseñanza primaria, secundaria y universitaria en la misma ciudad; d) todos son hijos de hispanohablantes. Las entrevistas incluyen diferentes situaciones comunicativas: entrevistas informales y formales entre el informante y la entrevistadora, diálogos entre dos informantes y conferencias. Los temas son libres y tienen relación con la vida y la profesión de los informantes. Nunca se consideró el habla de la entrevistadora como material de análisis.

\section{La perífrasis ir a + infinitivo: consideraciones generales}

La perífrasis ir a + inifinitivo es de formación tardía y su origen hay que buscarlo en el empleo de ir acompañado de un infinitivo en contextos en los que ir indicaba un movimiento físico para realizar la acción, pero en los que fácilmente el movimiento pasaba a segundo plano y se destacaba principalmente la acción futura. En el siglo XIII, ir (a) + infinitivo está documentada para denotar la preparación o disposición para la acción y la acción próxima. En el siglo XIV expresa ya, con el auxiliar en imperfecto, la acción inminente usualmente frustrada. Para indicar un futuro próximo está registrada en la segunda mitad del siglo XV. En este siglo también empieza a predominar la forma con la preposición a (A. Yllera 1980: 171, 175). En cuanto al español de Costa Rica, está documentado que la perífrasis sustituye el futuro de indicativo en documentos escritos a partir de la segunda mitad del siglo XVIII (M. A. Quesada Pacheco 1990: 115) ${ }^{1}$.

En el español moderno, Lenz (1925: §268) incluye ir a + infinitivo entre las perífrasis progresivas, que indican acciones que se verificarán en el futuro inmediato. M. Seco (1991: 220-221) atribuye a esta perífrasis dos valores: "intención" y "acción futura", y agrega que "ir $a+$ infinitivo (...) indica una acción futura que se ve más inmediata al presente, o más viva, o más voluntaria, que la expresada por el tiempo llamado futuro: tal es la diferencia entre vamos a hacer una excursión y haremos una excursión". 
La Real Academia Española (1973: 445-446), por su parte, señala que todas las perífrasis con infinitivo tienen "un sentido general de acción dirigida hacia el futuro". No obstante, al hablar de la perífrasis ir a + infinitivo, destaca su valor aspectual incoativo: "Ir $a+$ infinitivo significa acción que comienza a efectuarse, bien en la intención, bien en la realidad objetiva”. También Gómez Torrego (1999: 3365) opina que el aspecto, junto con el valor temporal de futuridad, son los valores dominantes de esta perífrasis, y por eso la incluye entre las perífrasis aspectuales.

Bauhr (1989: 68), en cambio, en un estudio sobre el empleo del futuro en -ré y la perífrasis verbal ir a + infinitivo en algunas obras teatrales modernas españolas, llega a la conclusión de que las dos formas son de valor aspectual neutro, y si expresan algún valor aspectual, éste se debe al significado léxico del verbo, es decir, al modo de acción:

(...) tanto cantaré como voy a cantar son formas temporal-modales. Los valores aspectuales que se observan en ellas son siempre de carácter léxico-contextual. La categoría del aspecto no desempeña una función gramatical relevante para la descripción de ninguna de estas dos formas.

Para designar acciones futuras, el español moderno emplea, aparte de la perífrasis ir a + infinitivo, otras dos formas: el futuro de indicativo y el presente de indicativo. Según afirma Moreno de Alba (1985: 93), no parece fácil “establecer en qué ocasiones o en qué entornos sintácticos, o con qué clase de verbos, o con qué tipo de hablantes puede percibirse una preferencia por determinada variante". Y, refiriéndose al español mexicano, concluye que el empleo de las tres variantes tiene una distribución libre. ${ }^{2}$

Sin embargo, se han señalado distintas variables que podrían condicionar la alternancia entre el futuro de indicativo y la perífrasis ir a + infinitivo (M. Sedano 1994: 226). Entre estas variables encontramos, por ejemplo, el estilo empleado, la inmediatez o alejamiento de la acción futura, la determinación o la indeterminación del tiempo en que se realizará la acción dada, así como la conexión o desconexión de la acción con el presente del hablante.

Bauhr (1989: 347-349), a su vez, afirma que a nivel temporal, el futuro indica una relación de posterioridad al origen, mientras que la perífrasis ir a + infinitivo indica una relación de posterioridad a la situación simultánea al origen. En lo que se refiere a la modalidad, este autor piensa que los matices modales más frecuentes de la forma cantaré son el de intención, probabilidad y posibilidad, mientras que en el caso de la perífrasis las más frecuentes son las modalidades negadas no debido y no posible y las afirmativas seguro y necesario.

Al estudiar el uso de estas dos formas en el español hablado de Venezuela, Sedano (1994: 236, 238) llega a la conclusión de que cantaré se emplea en los casos de distancia temporal lejana y en las modalidades epistémicas de duda, conjetura o cálculo, mientras que voy a cantar puede emplearse para cualquier distancia temporal, pero tiene un uso predominante cuando la acción futura se presenta como inmediata o próxima, así como para la expresión de la intención del hablante y de la modalidad epistémica de seguridad o convencimiento. El uso del futuro morfológico, sin embargo, lo encuentra mucho más restringido que el uso del futuro perifrástico que, por eso, considera como "la verdadera expresión de futuro en el español actual"'.

En cuanto al presente, M. Alonso (1974: 137) opina que la forma canto añade a la acción futura "una resolución y seguridad de que el hecho que todavía es eventual ha de ser una realidad". A Moreno de Alba (1977: 137), por otra parte, le parece que el presente expresa un futuro más inmediato que las otras dos formas verbales. ${ }^{3}$ 


\section{Los valores de ir a + infinitivo}

En el corpus usado para esta investigación aparecen 303 casos de la perífrasis ir a + infinitivo. En 237 ocasiones el auxiliar está en presente de indicativo; en 57, en pretérito imperfecto de indicativo; en 2, en pretérito perfecto simple de indicativo; en 2, en futuro de indicativo; en 2, en presente de subjuntivo; y en 3 casos está en pretérito imperfecto de subjuntivo. Antes de asignar los valores, clasificamos todas las formas documentadas en tres grupos según el tiempo verbal en que se halla el auxiliar: 1) con el verbo ir en presente de indicativo; 2) con el verbo ir en pretérito imperfecto de indicativo; 3) con el verbo ir en otros tiempos.

Los valores los dividimos en dos grupos principales. En el primer grupo recogemos los casos en los cuales la perífrasis se caracteriza solamente por su valor temporal, es decir, cuando denota una acción posterior con respecto al punto de referencia dado, sea el momento del habla o sea otro punto de referencia determinado por el contexto. En el segundo grupo entran los casos en los cuales esta forma verbal se caracteriza por alguno de los diferentes valores modales, aspectuales o estilísticos que puede adquirir. Aquí, sin embargo, hay que subrayar que a veces la frontera entre estos valores y el valor temporal se torna bastante borrosa y que hasta pueden fundirse.

\subsection{Valores de ir a + infinitivo con el verbo ir en presente de indicativo (237 casos; 78,2\%)}

\subsubsection{Valores temporales (211 casos; 69,6\%)}

1. Valor de futuro cercano o próximo (43 casos; $14,2 \%$ ) cuando la perífrasis se refiere a acciones posteriores al momento del habla que se perciben temporalmente como próximas. El carácter cercano de la acción verbal se reconoce bien por el contexto, o bien por la presencia de alguna marca de cercanía temporal (p.ej. los adverbios ya o ahora):

(1) Y le digo yo: "Bueno yo ya voy a terminar mi bachillerato." [YS: 27]

(2) ¿Qué va a pasar ahora? [YS: 134]

(3) Bueno, aquí voy a meter las patas porque no sé nada de esto. [YS: 145]

(4) Le voy a contar una cosa y no lo va a creer y le va a dar risa. [YS: 146]

2. Valor de futuro general (138 casos; 45,5\%) cuando ir a + infinitivo expresa acciones posteriores con respecto al momento del habla, pero que no se perciben como próximas o inmediatas. Véanse los ejemplos:

(5) Eso se va a dragar y se le va a quitar toda una gramínea que lo invadió. [YS: 43]

(6) Aquí tengo una ponencia de él que vamos a publicar sobre la lengua española y la sociedad colonial. [YS: 192] 
PITLOUN: La perífrasis ir a + infinitivo y la expresión de la posterioridad en el habla culta...

(7) Entonces esa cooperativa va a tener los médicos sin sueldo, que van a ser dueños de la clínica y que van a hacer que la gente vaya ahí a buscar a cada uno. [YS: 236]

(8) Van a hacer un homenaje y me van a entregar... y yo en ese homenaje voy a devolver la donación (...) [YS: 271]

3. Valor de futuro histórico (19 casos; 6,3\%) cuando la perífrasis denota una acción posterior a un momento presente que en este caso no coincide con el momento del habla, sino que se identifica con un hecho pasado. Así,

(9) Carrillo en realidad nos va a independizar, en el aspecto de códigos, de España, en el año mil ochocientos cuarenta y uno (...). [YS: 310]

(10) En mil novecientos surge una nueva generación que es la que va a darle por la pluma de Rodó (...) el planteamiento más claro que hasta entonces se hace sobre los problemas latinoamericanos. [YS: 302]

(11) (...) y se constituye ahí una provincia de Tagusgalpa, que va a ser una provincia marginal. [YS: 287]

4. En oraciones condicionales (11 casos; 3,6\%) que expresan acciones que pueden ocurrir en el futuro si se cumple la condición dada. En 4 ocasiones aparece ir a + infinitivo en la prótasis; en 7, en la apódosis. Ejemplos:

(12) Entonces... San José, si usted va a ir... [YS: 71]

(13) O sea, si llega un maleante y lo agarran entre cinco ahí (...) el maleante va a salir perdiendo, verdad. [YS: 71]

(14) Si el día de mañana necesito trabajar, pues, gracias a Dios, voy a poder hacerlo. [YS: 25]

\subsubsection{Valores no temporales (26 casos; $8,6 \%)$}

1. Valor imperativo (3 casos; 1\%), cuando la perífrasis se emplea para dar órdenes de una manera más atenuada o, como la RAE (1973: 130) lo señala para el futuro de indicativo, "para reforzar la voluntad imperativa expresando seguridad en el cumplimiento de lo mandado". Por ejemplo:

(15) Van a fotocopiar este libro entero (...) y el último día me lo van a traer empastado. [YS: 139]

(16) Pero no es secta. Vas a perdonar. [YS: 55] 
2. Valor lexicalizado (3 casos; $1 \%$ ) cuando ir a + infinitivo se emplea como una frase fija bien para indicar "curiosidad o expectación hacia algo" (Gómez Manzano 1992: 118), o bien, encabezada por qué, para expresar "resignación ante algún contratiempo" (Gómez Torrego 1999: 3372). Así,

(17) Y si no van a clases pues se quedan. Y pierden los años y se acabó. ¡Qué vamos a hacer! [YS: 48]

(18) Vamos a ver qué pasa dentro de un... [YS: 31]

3. Valor expresivo o retórico (16 casos; 5,3\%) cuando la perífrasis aparece en contextos exclamativo-interrogativos en los cuales se hace resaltar "una obligación o capacitación afirmando cuando hay negación, y negando cuando no hay negación" (Gómez Torrego 1999: 3370). Ejemplos:

(19) ¿Por qué no voy yo a poder hacerlo? [YS: 219] (= "claro que yo puedo hacerlo")

(20) ¿Quién va a querer dar esos cursos? [YS: 140] (= "nadie puede querer darlos")

(21) ¿Cómo va a pagar esa... esa persona seis mil colones? [YS: 111] (= "no puede pagarlos")

(22) Es más para qué va a correr, (...) [YS: 233] (= "no tiene que correr")

4. Valor dubitativo (4 casos; $1,3 \%$ ), cuando ir a + infinitivo denota duda añadida o no al valor temporal:

(23) ¿Cómo va a ser sujeto, eso va a ser sujeto? [YS: 137]

(24) Yo no sé de dónde los van a coger. [YS: 101]

2.2. Valores de ir a + infinitivo con el verbo ir en pretérito imperfecto de indicativo (57 casos; $18,8 \%$ )

\subsubsection{Valores temporales (29 casos; $9,6 \%)$}

1. Valor de futuro relacionado con un hecho pasado (19 casos; 6,3\%) cuando la perífrasis expresa acciones posteriores con respecto a un punto de referencia anterior al momento del habla. En estos casos iba a cantar puede alternar con cantaría. Ejemplos: 
PITLOUN: La perífrasis ir a + infinitivo y la expresión de la posterioridad en el habla culta...

(25) Yo creía que habiendo estudiado Historia no me iban a admitir. [YS: 58]

(26) Y lo dimos muy bien dado y con mucho cariño porque sabíamos que no nos lo iban a pagar. [YS: 139]

(27) Por ejemplo, este domingo anunciaron que no iba a haber luz donde yo vivo (...) [YS: 252]

2. Valor inminencial (10 casos; 3,3\%) cuando ir a + infinitivo se refiere a acciones que estaban a punto de efectuarse en un momento pasado y que más tarde efectivamente llegaron a realizarse. Lo que distingue este grupo del anterior es que aquí la perífrasis no se puede sustituir por el condicional. Por ejemplo:

(28) Y entonces cuando yo iba a entrar a la Universidad fui una vez a la Escuela de Arquitectura y de repente no me gustó como el ambiente. [YS: 15]

(29) [¿Y qué eran?] Los exámenes de diagnóstico que iban a hacer. [YS: 141]

(30) A mí me sonó lindísimo porque - diay - yo lo iba a hacer ahí, sentada en el escritorio de mi casa. Sí. Me pasaban el inventario y (...) [YS: 150]

\subsubsection{Valores no temporales (28 casos; 9,2\%)}

1. Valor intencional o de conato (21 casos; 6,9\%) cuando la perífrasis indica acciones pasadas que se inician o se intentan, pero no llegan a consumarse porque interviene alguien o algo que impide su realización. Véanse los ejemplos:

(31) (...) y andaba el run run de que la iban a cerrar. [YS: 125]

(32) Me iban a pasar a emergencias. [YS: 171]

(33) Bueno, la parte de parque, esa se iba a desarrollar sobre todo para atraer turismo científico, (...) [YS: 267]

2. Valor expresivo o retórico (4 casos; $1,3 \%$ ) cuando, como en los casos con el auxiliar en presente de indicativo, ir a + infinitivo en las oraciones exclamativo-interrogativas destaca la (im)posibilidad de que suceda lo denotado por el infinitivo. En este caso, obviamente, se trata de acciones pasadas. Por ejemplo:

(34) ¿Entonces qué se iba a quedar haciendo ahí? [YS: 211] (= "no tenía nada que hacer allí’')

(35) ¿A quién se le iba a olvidar eso? A nadie se le olvidaba. [YS: 295] (= "a nadie se le podía olvidar eso") 
3. Valor hipotético (3 casos; $1 \%$ ), cuando la forma voy a cantar se refiere a las acciones no realizadas en el pasado y equivale a habría cantado (o hubiera/hubiese cantado). Así:

(36) Cuando llegué a cuarto año de Farmacia me mandaron a llamar para el primer cur... grupo de Medicina. Ya jamás me iba a pasar de Facultad. [YS: 143]

(37) (...) qué hacía yo si a ese chiquito le daba una intoxicación y me iban a acusar penalmente de haber... [YS: 151]

\subsection{Valores de ir a + infinitivo con el verbo ir en otros tiempos (9 casos; 3\%)}

2.3.1. Con el verbo ir en pretérito perfecto simple de indicativo (2 casos; $0,66 \%$ )

Hemos registrado dos casos cuando el auxiliar aparece en pretérito perfecto simple de indicativo. En ambos la perífrasis tiene valor temporal y denota una acción inminente. Por ejemplo:

(38) ... cuando me fui a casar en el ochenta y dos, (...) fue la época en que empezó la crisis. [YS: 202]

\subsubsection{Con el verbo ir en futuro de indicativo (2 casos; 0,66\%)}

En dos casos que hemos documentado, el auxiliar está en futuro de indicativo. En ambos casos la perífrasis presenta el valor modal: en el primero, el valor expresivo-exclamativo, y en el segundo, el dubitativo. Creemos que en el primer caso el hablante emplea el futuro para subrayar lo imposible que le parece la acción, y en el segundo, para reforzar la duda. Véase los ejemplos:

(39) A veces digo: “Cuándo iré a exponer yo?” Y como que se me puede hacer largo el asunto. [YS: 24] (= "nunca puedo exponer yo")

(40) Ahora que los muchachos no van a pagar pues no sé. No sé de dónde irán a agarrar para... [YS: 101]

\subsubsection{Con el verbo ir en presente de subjuntivo (2 casos; 0,66\%)}

En uno de los dos casos registrados con el auxiliar en presente de subjuntivo, la perífrasis aparece en una oración exclamativo-interrogativa. En el otro expresa una acción futura. Así,

(41) ¿Cómo es posible que usted se vaya a quedar? [YS: 116] (= "es imposible que se quede")

(42) No... no es que te vayás a morir de hambre ni mucho menos pero... pero son realmente limitantes. [YS: 203] 
PITLOUN: La perífrasis ir a + infinitivo y la expresión de la posterioridad en el habla culta...

\subsubsection{Con el verbo ir en pretérito imperfecto de subjuntivo (3 casos; 1\%)}

En tres casos detectados, el auxiliar está en pretérito imperfecto de subjuntivo. En dos de ellos, la forma ir a + infinitivo denota acciones futuras vistas desde un momento pasado, y en uno tiene el valor intencional, o de conato:

(43) Pero yo sé, estas becas imposible que me las fueran a dar - digamos - a mí. [YS: 54]

(44) Es una lástima que un trabajo así se fuera a perder.

\section{Resumen de los valores y su comparación con otros estudios}

Los valores de todas las formas de la perífrasis ir a + infinitivo documentadas se resumen en el cuadro 1 :

Cuadro 1. Resumen de los valores de la perífrasis ir a + infinitivo

\begin{tabular}{|l|c|c|c|}
\hline \multicolumn{1}{|c|}{ Valor } & N / \% & N / \% & N / \% \\
\hline Ir en presente de indicativo & & & $237 / 78,2$ \\
\hline Valores temporales & & $211 / 69,6$ & \\
\hline Futuro cercano & $43 / 14,2$ & & \\
\hline Futuro general & $138 / 45,5$ & & \\
\hline Futuro histórico & $19 / 6,3$ & & \\
\hline En las oraciones condicionales & $11 / 3,6$ & & \\
\hline Valores no temporales & & $26 / 8,6$ & \\
\hline Imperativo & $3 / 1$ & & \\
\hline Lexicalizado & $3 / 1$ & & \\
\hline Expresivo & $16 / 5,3$ & & \\
\hline Dubitativo & $4 / 1,3$ & & \\
\hline Ir en imperfecto de indicativo & & & $57 / 18,8$ \\
\hline Valores temporales & & $29 / 9,6$ & \\
\hline Futuro de un pretérito & $19 / 6,3$ & & \\
\hline Inminencial & $10 / 3,3$ & & \\
\hline Valores no temporales & & $28 / 9,2$ & \\
\hline Intencional & $21 / 6,9$ & & \\
\hline Expresivo & $4 / 1,3$ & & \\
\hline Hipotético & $303 / 103 / 100 \%$ \\
\hline Ir en otros tiempos & & $303 / 100 \%$ & \\
\hline Valores temporales & & & \\
\hline Valores no temporales & & & \\
\hline TOTAL & & & \\
\hline
\end{tabular}


En el cuadro 2, se muestra la distribución total de los valores temporales y no temporales de la perífrasis verbal que está bajo nuestro estudio:

Cuadro 2. Distribución de los valores temporales y no temporales de ir a + infinitivo.

\begin{tabular}{|l|c|c|c|}
\hline Ir a + infinitivo & Valores temporales & Valores no temporales & Total / \% \\
\hline Ir en presente de indicativo & 211 & 26 & $237 / 78,2$ \\
\hline Ir en imperfecto de indicativo & 29 & 28 & $57 / 18,8$ \\
\hline Ir en otros tiempos & 5 & 4 & $9 / 3$ \\
\hline Total / \% & $245 / 80,9$ & $58 / 19,1$ & $303 / 100 \%$ \\
\hline
\end{tabular}

Los resultados en el cuadro 1 y 2 indican lo siguiente:

a) la perífrasis ir a + infinitivo se usa en el español hablado de Costa Rica principalmente con el auxiliar en presente de indicativo (237 casos $=78,2 \%$ );

b) la perífrasis ir a + infinitivo se emplea mayormente con alguno de sus valores temporales $(245$ casos $=80,9 \%)$;

c) los valores temporales predominan sobre todo cuando el auxiliar está en presente de indicativo (211 casos $=89 \%$ del total de todos los casos cuando el auxiliar está en presente de indicativo), mientras que cuando el auxiliar está en imperfecto de indicativo, la distribución de los valores temporales $(29$ casos $=50,9 \%)$ y de los no temporales $(28$ casos $=49,1 \%$ ) es casi igual;

d) el valor principal con que aparece la perífrasis es el de futuro, sea éste inmediato o no $(192$ casos $=63,3 \%)$;

e) entre los valores no temporales destaca el valor expresivo en las oraciones exclamativointerrogativas $(22$ casos $=7,3 \%)$ y el valor intencional o de conato $(21$ casos $=6,9 \%)$. Estos dos valores equivalen a un $75 \%$ del total de todos los valores no temporales de ir a infinitivo.

En el cuadro 3 y 4 se comparan nuestros datos con los obtenidos por Troya Déniz en Las Palmas de Gran Canaria (1998: 80, 130-135) y por Gómez Manzano en Madrid (1992: 135) ${ }^{4}$ : 
PITLOUN: La perífrasis ir a + infinitivo y la expresión de la posterioridad en el habla culta...

Cuadro 3. Distribución de ir a + infinitivo según el tiempo en que se encuentra el verbo auxiliar en Costa Rica, Las Palmas de Gran Canaria y Madrid

\begin{tabular}{|c|c|c|c|}
\hline Ir a + infinitivo & $\begin{array}{c}\text { Costa Rica } \\
\text { N / \% }\end{array}$ & $\begin{array}{c}\text { Las Palmas } \\
\quad \text { N / \% }\end{array}$ & $\begin{array}{c}\text { Madrid } \\
\text { N / \% }\end{array}$ \\
\hline Ir en presente de indicativo & $237 / 78,2$ & $322 / 83$ & $625 / 83,56$ \\
\hline Valores temporales & $211 / 69,6$ & $266 / 68,6$ & $561 / 75$ \\
\hline Valores no temporales & $26 / 8,6$ & $56 / 14,4$ & $64 / 8,56$ \\
\hline Ir en imperfecto de indicativo & $57 / 18,8$ & $54 / 13,9$ & $101 / 13,5$ \\
\hline Valores temporales & $29 / 9,6$ & $41 / 10,6$ & $51 / 6,8$ \\
\hline Valores no temporales & $28 / 9,2$ & $13 / 3,3$ & $50 / 6,7$ \\
\hline Ir en otros tiempos & $9 / 3$ & $12 / 3,1$ & $22 / 2,94$ \\
\hline Valores temporales & $5 / 1,7$ & $5 / 1,3$ & $13 / 1,74$ \\
\hline Valores no temporales & $4 / 1,3$ & $7 / 1,8$ & $9 / 1,2$ \\
\hline TOTAL & $303 / 100 \%$ & $388 / 100 \%$ & $748 / 100 \%$ \\
\hline
\end{tabular}

Cuadro 4. Distribución de los valores temporales y no temporales de ir a + infinitivo en Costa Rica, Las Palmas de Gran Canaria y Madrid

\begin{tabular}{|l|c|c|c|}
\hline \multicolumn{1}{|c|}{ Ir a + infinitivo } & $\begin{array}{c}\text { Costa Rica } \\
\mathbf{N} / \%\end{array}$ & $\begin{array}{c}\text { Las Palmas } \\
\mathbf{N} / \%\end{array}$ & $\begin{array}{c}\text { Madrid } \\
\mathbf{N} / \%\end{array}$ \\
\hline Valores temporales & $240 / 80,9$ & $312 / 80,5$ & $625 / 83,54$ \\
\hline Valores no temporales & $57 / 19,1$ & $76 / 19,5$ & $123 / 16,46$ \\
\hline TOTAL & $297 / 100 \%$ & $388 / 100 \%$ & $748 / 100 \%$ \\
\hline
\end{tabular}

Si comparamos los datos de Costa Rica con los de las investigaciones realizadas en las otras dos zonas de habla hispana, observamos lo siguiente:

a) en los tres lugares, la perífrasis se usa principalmente con el auxiliar en presente de indicativo; 
b) en los tres lugares predominan los valores temporales de la perífrasis sobre los no temporales;

c) en Costa Rica la incidencia de ir a + infinitivo con el auxiliar en pretérito imperfecto de indicativo es más elevada (en un 5\%) que en Las Palmas de Gran Canaria y en Madrid;

d) en las tres regiones, la frecuencia de la perífrasis con el auxiliar en otros tiempos es casi la misma;

e) en Costa Rica y en Las Palmas de Gran Canaria, el empleo no temporal de la perífrasis es más frecuente que en Madrid;

f) en Las Palmas de Gran Canaria el uso no temporal de ir a + infinitivo con el auxiliar en presente de indicativo es más elevado $(17,4 \%)$ que en Costa Rica (11\%) y en Madrid $(10,2 \%)$, mientras que su uso no temporal con el auxiliar en pretérito imperfecto de indicativo es en Las Palmas de Gran Canaria más bajo $(24,1 \%)$ que en los otros dos lugares (49,1\% en Costa Rica y 49,5\% en Madrid).

\section{4. $\quad$ Expresión de la posterioridad}

\subsection{Posterioridad al momento del habla}

En todo el corpus que estamos manejando para este estudio, hemos encontrado 301 casos que indican una acción posterior al momento en que se habla. La incidencia de las formas que el idioma español emplea para expresar esta relación temporal la resumimos de la siguiente manera ${ }^{5}$ :

Cuadro 5. Distribución de formas para la expresión de futuro

\begin{tabular}{|l|c|}
\hline Posterioridad al momento del habla & Total / \% \\
\hline Ir a + infinitivo & $181 / 60,1$ \\
\hline Presente de indicativo & $110 / 36,6$ \\
\hline Futuro de indicativo & $10 / 3,3$ \\
\hline Total & $301 / 100 \%$ \\
\hline
\end{tabular}

Como se puede apreciar, la forma que se presenta en mayor cantidad es ir a + infinitivo, registrada en un 60,1\% de los casos. En el segundo lugar encontramos la forma canto con 
un 36,6\%. La forma cantaré, que alcanza apenas un 3,3\%, es, pues, la forma menos empleada por los hablantes costarricenses en los contextos que están bajo nuestro estudio. Si comparamos estos datos con los de la investigación realizada por Moreno de Alba en México (1985: 33, 95), observamos que el cuadro es un poco diferente. También en México predomina la perífrasis, pero cantaré registra un porcentaje bastante elevado y casi igual al de la forma canto:

\section{Cuadro 6. Distribución de formas para la expresión de futuro en Costa Rica y México}

\begin{tabular}{|l|c|c|}
\hline & Costa Rica / \% & México / \% \\
\hline voy a cantar & 60,1 & 51 \\
\hline cantaré & 3,3 & 23,2 \\
\hline canto & 36,6 & 25,8 \\
\hline
\end{tabular}

En lo que se refiere al uso del futuro de indicativo ${ }^{6}$, podemos hacer un par de observaciones que, al mismo tiempo, pueden ayudarnos a trazar la línea divisoria entre esta forma y la perífrasis ir a + infinitivo. Primero, todos los casos registrados del futuro de indicativo con valor temporal corresponden a la tercera (56 años y más; 6 casos) y a la segunda generación (36-55 años; 4 casos), teniendo el informante más joven que la emplea 44 años. Segundo, la mitad de todos los casos de esta forma la registramos solamente en dos informantes que, además, estaban dando sus conferencias, es decir, que se encontraban en un ambiente que influye en la manera de expresarse. Tercero, cantaré siempre denota acciones temporalmente no fijadas, esto es, nunca aparece con alguna marca temporal (p.ej. mañana, el año que viene), y, por lo general, no se refiere a personas, cosas o situaciones concretas. Véanse los ejemplos:

(45) Hay alguno que otro resentido, resentido social, pues, que [toda persona] recordará con dolor. [YS: 166]

(46) El profesor que no respeta al alumno no será respetado también por el alumno. [YS: 177]

(47) Y al tener mucho estímulo económicamente, pues [el personal de preescolar y de primaria] se tendrá que superar. [YS: 331]

En cuanto al empleo del presente de indicativo, nos parece que la mayoría de veces el hablante acude a esta forma cuando hay resolución, seguridad, certeza o convencimiento, porque ni el contexto ni las marcas temporales que acompañan al verbo indican que se trate del futuro inmediato. Por ejemplo:

(48) Hoy te las vendo. [YS: 23]

(49) Diay no sé, en el futuro [la ciudad] no tiene donde expander ahí. [YS: 69] 
(50) Es un mandado y C.E. va también (...). [YS: 140]

(51) (...) yo renuncio dentro de quince días a la Reserva Forestal. [YS: 271]

Esta diferencia entre canto y voy a cantar puede ilustrarse con los siguientes dos ejemplos sacados de la misma informante:

(52) Y entonces ya terminando esto el año entrante ya puedo llevar este... investigación dirigida para hacer tesis. [YS: 16]

(53) Ora, si el día de mañana necesito trabajar, pues, gracias a Dios voy a poder hacerlo. [YS: 25]

Sin embargo, el uso del presente de indicativo con este valor del futuro seguro parece estar condicionado por el contexto, por la ausencia de la marca temporal o por el tipo del verbo. Esto lo demuestran los siguientes ejemplos, en los cuales, aunque se trata de acciones futuras seguras, se emplea la perífrasis, porque al usar el presente, el sentido de la oración cambiaría. Así,

(54) O sea, ya hay una buena cantidad de materiales y ellos van a redactar un libro. [YS: 59]

(55) (...) donde se anotan todos los códigos de los cursos, verdad, que se van a dictar en esa sala de clase (...). [YS: 116]

(56) Este año voy a dar un grupo Historia de las Instituciones de Costa Rica. [YS: 186]

A veces, no obstante, la forma canto denota acciones inmediatamente posteriores al momento del habla. Parece que en estos casos no siempre es sustituible por la perífrasis. Ejemplos:

(57) ¿Cuánto tiempo al chiquito le dejo este... este juego? [YS: 98]

(58) ¿Y ahora qué hacemos? [YS: 222]

(59) ¿Qué hago? ¿Para dónde voy? [YS: 250]

(60) Bueno, hasta mañana. Ya me voy. [YS: 105]

(61) Bueno usted sabe si lo compra aquí o va y hace cola en la farmacia de La Caja para que se lo den. [YS: 147]

En algunos casos el presente aparece con la perífrasis en una secuencia de dos sucesos donde el presente indica el primero. Así,

(62) Bueno los mando a ver una obra de teatro, tal vez les guste el teatro y de ahora en adelante van a seguir yendo. [YS: 137] 
(63) Las mañas que no aprende en la casa las va a aprender en la calle. [YS: 104]

Entre las estructuras que parecen "favorecer" el uso de la forma canto hemos encontrado dos: a) la expresión a ver (o para ver) + si (o un pronombre o adverbio interrogativo); b) las preguntas introducidas por ¿por qué no...? Ejemplos:

(64) (...) hay que esperar a ver qué pasa. [YS: 97]

(65) (...) y empieza como a desmenuzar para ver con qué se queda. [YS: 129]

(66) Es que a ver si... a ver si aprende (...). [YS: 339]

(67) ¿Por qué no le pones estos zapatitos? [YS: 105]

(68) ¿Por qué no hacemos una cosa? [YS: 149]

\subsection{Posterioridad a un hecho pasado}

En cuanto a la expresión de acciones posteriores a un punto de referencia anterior al momento del habla, hemos atestiguado en total 42 casos. La distribución de las formas es la siguiente:

\section{Cuadro 7. Distribución de formas para la expresión de posterioridad a un hecho pasado}

\begin{tabular}{|l|c|}
\hline Posterioridad a un hecho pasado & Total / \% \\
\hline Ir a + infinitivo & $19 / 45,2$ \\
\hline Condicional & $23 / 54,8$ \\
\hline Total & $42 / 100 \%$ \\
\hline
\end{tabular}

En este caso, el porcentaje más elevado, que equivale a un 54,8\%, lo muestra la forma cantaría. La perífrasis ir a + infinitivo obtiene un 45,2\%. A pesar de este resultado, nos permitiríamos señalar la perífrasis como la forma más corriente, porque, primero, la perífrasis la emplean 12 informantes, mientras que el condicional 8 (las dos formas las detectamos solamente en dos informantes), y, segundo, 14 casos del condicional, es decir, más de la mitad, los documentamos tan sólo en dos informantes, quienes hablan sobre los temas de la historia de Costa Rica. 


\section{Conclusiones}

La perífrasis ir a + infinitivo se emplea en el habla culta de Costa Rica principalmente con el auxiliar en presente de indicativo para indicar acciones posteriores al momento en que se habla: el 64,7\% del total de todos los casos registrados corresponden a este valor temporal. En general, sus valores temporales predominan significativamente sobre los no temporales.

La perífrasis es la forma más usada para expresar acciones posteriores con respecto al momento del habla. Los hablantes costarricenses acuden a la perífrasis en un $60,1 \%$ de todos los casos documentados de este tipo de acciones.

En cuanto a la posterioridad a un hecho pasado, la perífrasis muestra un porcentaje un poco más bajo que el condicional; pero, por las razones que hemos mencionado más arriba, la consideramos como la forma más extendida.

\section{Notas}

1. Cómo la perífrasis ir a + infinitivo iba cobrando fuerza lo demuestra el estudio de Sáez Godoy (1968), quien observó la expresión del futuro en varias obras teatrales españolas que corresponden a tres diferentes épocas: al siglo XVII (Cervantes y Lope de Vega), al siglo XIX (Bretón de los Herreros) y al siglo XX (García Lorca y otros tres autores que representan la segunda mitad de este siglo). La forma más empleada en todas estas obras es el futuro sintético cantaré, que hasta García Lorca muestra una incidencia entre un 78 y $82 \%$. En los autores más modernos, sin embargo, su porcentaje baja a un $62 \%$. La perífrasis, en cambio, no aparece ni una sola vez en Cervantes, y en Lope de Vega obtiene un $2 \%$. Su porcentaje, no obstante, sube a un $6 \%$ en Bretón, a un 15\% en García Lorca y en los autores más modernos ya llega a un 33\%. Digno de señalar es el hecho de que el aumento de ir a + infinitivo en García Lorca se produce sobre todo a expensas de la perífrasis haber de + infinitivo, que en Lope de Vega alcanza un $18 \%$, pero en los autores modernos ya casi desaparece con significado futuro; y que apenas en los autores de la segunda mitad del siglo XX el creciente empleo de la perífrasis ocurre en detrimento de la forma cantaré. En cuanto a los valores de ir a + infinitivo, Sáez Godoy afirma (p. 1887) que "primitivamente significó el futuro inmediato, pero actualmente se ha extendido hasta servir para indicar el futuro en general".

2. En otra ocasión, no obstante, Moreno de Alba (1977: 137) aduce, basándose en los ejemplos recopilados para su estudio, algunos casos en que se manifiesta cierta preferencia por una u otra forma. De acuerdo con él, el futuro es la forma predominante en los siguientes entornos sintácticos: 1) en la apódosis de las oraciones condicionales («Si es una persona culta, podrá representar al país»; 2) en las oraciones objetivas que presentan el mismo sujeto de la principal («Yo creo que nunca lo dejaré»); 3) en algunos clichés («Bueno ... te diré, ninguno de los dos me gusta»).

3. Entre las estructuras que "favorecen y a veces exigen" el uso del presente, Moreno de Alba (1985: 3435) menciona, por ejemplo, las siguientes: 1) después de la expresión a ver si («Voy a ver si lo busco y si le doy a...»); 2) en enunciados que se refieren a un futuro marcadamente inmediato, sobre todo con el verbo $\operatorname{ir}(s e)$ («Ya me voy a trabajar»); 3) en oraciones interrogativas directas, también en referencia a un futuro muy próximo («iPongo la mesa, mamá?»); 4) en oraciones objetivas directas del verbo ver en futuro («Haré un sacrificio más, veré qué hago, pero yo...»); 5) en relación con la construcción cuando guste (quiera, le parezca, etc.) («Cuando guste se lo presto con mucho gusto»).

4. Las dos autoras también estudiaron el habla culta y trabajaron con un material recogido según los principios generales del Proyecto. 
5. No consideramos los siguientes casos: 1) el empleo de estas formas en las oraciones condicionales, puesto que el uso del futuro sintético está restringido en este tipo de oraciones; 2) los empleos "históricos" de estas formas, ya que el significado del futuro histórico y del presente histórico no es el mismo; y 3) las apariciones de la frase "lo que ha de pasar pasará", la cual los informantes generalmente repiten con la entrevistadora.

6. En total hemos registrado 51 casos del futuro de indicativo, de los cuales $16(31,4 \%)$ corresponden al uso temporal (incluyendo el futuro histórico, la apódosis y las frases hechas) y 35 (68,6\%), al uso modal. Los valores modales más frecuentes son el de suposición o conjetura (15 casos; 29,4\%) y el dubitativo (11 casos; 21,6\%).

\section{Bibliografía}

Alonso, Martin. 1974. Gramática del español contemporáneo. Madrid: Guadarrama.

Bauhr, Gerhard. 1989. El futuro en -ré e ir a + infinitivo en español peninsular moderno. Gotemburgo: Acta Universitatis Gothoburgensis.

Comisión de Lingüística Hispanoamericana del P.I.L.E.I. 1977. Estudios sobre el español hablado en las principales ciudades de América. México: Universidad Nacional Autónoma de México.

Fernández de Castro, Félix. 1999. Las perífrasis verbales en el español actual. Madrid: Gredos.

Gómez Manzano, Pilar. 1992. Perífrasis verbales con infinitivo (Valores y usos en la lengua hablada). Madrid: U.N.E.D.

Gómez Torrego, Leonardo. 1999. "Los verbos auxiliares. Las perífrasis verbales de infinitivo". En Real Academia Española, 3323-3389.

Iuliano, Rosalba, 1975. "La perífrasis ir + a + (infinitivo) en el habla culta de Caracas". En 1975 Colloquium on Hispanic Linguistics. Washington: Georgetown University Press, 59-66.

Lenz, Rodolfo. 1925. La oración y sus partes. Madrid: Centro de Estudios Históricos.

Moreno de Alba, José. G. 1977. "Vitalidad del futuro de indicativo en la norma culta del español hablado en México". En Comisión de Lingüística Hispanoamericana del P.I.L.E.I., $129-146$.

1985. Valores de las formas verbales en el español de México. México: Universidad Nacional Autónoma de México. 
Quesada Pacheco, Miguel Ángel. 1990. El español colonial de Costa Rica. San José: Editorial de la Universidad de Costa Rica.

Real Academia Española. 1973. Esbozo de una nueva gramática de la lengua española. Madrid: Espasa.

Gramática descriptiva de la lengua española. Dirigida por Ignacio Bosque y Violeta Demonte. Madrid: Espasa.

Sáez-Godoy, Leopoldo. 1968. "Algunas observaciones sobre la expresión del futuro en español”. En Actas del XI Congreso Internacional de Lingüística y Filología Románicas IV. Madrid: C.S.I.C., 1875-1889.

Seco, Manuel. 1991. Gramática esencial del español. Introducción al estudio de la lengua. Madrid: Espasa Calpe.

Seco, Rafael. 1975. Manual de gramática española. Madrid: Aguilar.

Sedano, Mercedes. 1994. "El futuro morfológico y la expresión ir a + infinitivo en el español hablado de Venezuela". Verba. 21: 225-240.

Solano Rojas, Yamilet. 1989. El habla culta costarricense (Materiales para su estudio). Universidad Nacional Autónoma de México.

Troya Déniz, Magnolia. 1998. Perífrasis verbales de infinitivo en la norma lingüística culta de Las Palmas de Gran Canaria. Madrid: Real Academia Española.

Yllera, Alicia. 1980. Sintaxis histórica del verbo español: Las perífrasis medievales. Zaragoza: Universidad de Zaragoza. 